\title{
Correction to: Impact: Design With All Senses
}

Christoph Gengnagel, Olivier Baverel, Jane Burry, Mette Ramsgaard Thomsen, and Stefan Weinzierl

\section{Correction to: \\ C. Gengnagel et al. (Eds.): Impact: Design With All Senses, https://doi.org/10.1007/978-3-030-29829-6}

In the original version of the book, the following belated corrections have been Incorporated:

In the chapter "Design and Structural Modelling of Surface-Active Timber Structures Made from Curved CLT - Urbach Tower, Remstal Gartenschau 2019”, all the images were published with low quality. This has been updated with high-resolution images.

In the chapter "Mediating Irregularity: Towards a Design Method for Spatial Structures Utilizing Naturally Grown Forked Branches", the affiliations of the authors Lukas Allner, Daniela Kroehnert, and Andrea Rossi were incorrect. These have been corrected.

Correct Affiliations

Lukas Allner

University of Applied Arts Vienna, Vienna, Austria

Daniela Kroehnert

University of Applied Arts Vienna, Vienna, Austria

Andrea Rossi

Technical University Darmstadt, Darmstadt, Germany

The updated version of these chapters can be found at

https://doi.org/10.1007/978-3-030-29829-6_33

https://doi.org/10.1007/978-3-030-29829-6_34 